\title{
EDUCAÇÃO INTEGRAL, ESCOLA DE TEMPO INTEGRAL: UM DIÁLOGO SOBRE OS TEMPOS
}

\author{
Mariana Roveroni ${ }^{1}$ (1) \\ Adriana Missae Momma ${ }^{2}$ (1) \\ Bruna Cirino Guimaräes ${ }^{2}$ (D)
}

\begin{abstract}
RESUMO: O presente texto propóe-se a trazer indagaçóes sobre a escola de tempo integral e a educaçáo integral no contexto atual. Essa reflexáo implica a leitura do contexto e do cenário social e político, nos quais as concepçôes de educação e sociedade sáo forjadas atreladas aos ditames da economia global. Em termos sociológicos, a educação integral faz um chamamento contrário à visão fragmentada do ser, da vida, do tempo, mas, por outro lado, em termos políticos, não altera drasticamente a realidade, mantendo o conjunto de contradiçóes socioeconômicas, de classe, acirrando a exclusão em escala global.
\end{abstract}

Palavras-chave: Escola integral. Escola de tempo integral. Educação integral. Tempos.

\section{Full-time Education, Full-time School: a dialogue on the times}

ABSTRACT: The present text proposes to bring inquiries about the "full-time school" and "full-time education" in the current

\footnotetext{
${ }^{1}$ Prefeitura de Campinas - Campinas (SP), Brasil. E-mail: mariana_roveroni@yahoo.com.br ${ }^{2}$ Universidade Estadual de Campinas - Campinas (SP), Brasil. E-mails: adrianamomma@gmail.com; brunacirinog@gmail.com DOI: $10.1590 /$ CC0101-32622019219069
} 
context. This reflection implies the reading of the context and social and political scenario in which the conceptions of education and society are forged tied to the dictates of global economy. In sociological terms, full-time education makes a contrary call to the fragmented vision of being, of life, of time... But on the other hand, in political terms, it does not drastically alter reality, maintaining the set of socioeconomic and class contradictions, exacerbating exclusion on a global scale.

Keywords: Full-time School; School of Integral Time; Full-time Education; Times.

\section{INTRODUÇÃO}

noção de tempo constitui algo inerente à nossa condição humana, que habita um planeta e que, por sua vez, faz parte 1 de um universo. Nessa dimensão cósmica infinita, a nossa condição objetiva/subjetiva finita impóe-nos um exercício constante de significação e ressignificação dos tempos/espaços. Estou com fome? Estou com sede? Como determinado acontecimento marcou você? Nessa época, seus pais eram jovens? Quantos anos eles tinham? Em que momento vamos descansar? Já faz tempo que não encontro aquele amigo. Por que tanto tempo dedicado à brincadeira e pouco tempo para demais afazeres? Vai dar tempo? Como organizo o meu dia hoje? Já está na hora de a minha filha aprender a ler e a escrever. Ele ainda é pequeno para fazer essa escolha. Quando eu tiver tempo, vou fazer... Ontem passei por uma situação inusitada. Futuramente tenho a intenção de...

Essas e muitas outras elaboraçóes evidenciam que a dimensão do tempo nos constitui e dão certa materialidade à nossa existência. Além do tempo corrido, do tempo do dia/tarde/noite/madrugada e do tempo das estaçóes, há aquela dimensão do tempo que marca a mente e os coraçóes humanos, o tempo que nos forma como identidade, subjetividade histórica.

Ultrapassando a lógica formal e métrica do tempo, muito alinhada ao relógio e situada num tempo histórico, social e político 
no qual time is money, tendo como marco a revolução industrial e seus fundamentos liberais, podemos reportar-nos à mitologia grega. Nesse contexto, deparamos com kairós, como aquele que se relaciona com o tempo da existência que se traduz pelo momento oportuno. Kairós é a entidade que revela o momento certo, a ocasião apropriada para agir.

Circunscritas num tempo histórico, social e político, a escola e as demais instituiçóes sociais não se apartam dessa reflexão. Afinal, como a organizaçáo dos tempos no contexto educacional (institucional) se configura? Quais são as contradições e tensões imanentes a essa dinâmica de trabalho/aprendizagem? Para além do tangível, há dimensóes predominantemente culturais que traduzem tais problemáticas e elas se evidenciam nas sutilezas do cotidiano. A dimensão do intangível, nesse sentido, tem uma força, pois nos remete à dimensão política e sociológico-cultural na qual o tempo toma formas e matizes que tocam em questóes centrais de cunho ideológico e não meramente terminológico, conceitual ou organizacional.

Como aponta o professor Agustín Escolano (2000, p. 533):

El tiempo escolar, elemento en apariencia estático en las estructuras de las organizaciones educativas, comienza en estos últimos años a ser objeto de análisis con la pretensión de su reconceptualización y modificación, lo que afectará en la praxis no sólo a los almanaques y horarios, sino a variables como el orden dentro del recinto docente y la comunidad educativa.

Com base nos estudos de Goergen (2005), problematiza-se a questão de que, mesmo diante do avanço tecnológico e da globalizaçáo econômica, marcadores da modernidade, o tempo na instituição socioeducativa possui ainda caráter rígido e inflexível e racionalidade marcada pela técnica, pela funcionalidade, pela objetividade e pela hierarquia. Os tempos escolares são divididos, separados e preestabelecidos "não apenas para otimizar a aprendizagem e menos ainda para libertar, agregar e solidarizar, mas para 
'vigiar e punir', para segregar e submeter" (FOUCAULT, 1987 apud GOERGEN, 2005, p. 10).

$\mathrm{O}$ autor compara as instituiçóes socioeducativas com quartéis militares e fábricas, onde há intenso exercício de poder. Há também o atrelamento aos critérios de eficiência e rigor, decorrentes do campo das ciências naturais. Portanto, reconhece que os tempos não estão organizados em função do ser humano enquanto sujeito e cidadão, mas sim da instrumentalização do ser humano em função de algo:

A escola se torna "curriculada", com seus tempos e espaços divididos, medidos, separados em razão de alguma coisa que o aluno não consegue entender. Introduz-se uma artificialidade ininteligível em função de algo supostamente útil. O tempo e o espaço são distribuídos e divididos em funçáo de alguma utilidade que fica subentendida numa rotina que é naturalizada (GOERGEN, 2005, p. 9).

Um dos maiores entraves contemporâneos existentes no contexto escolar está na tentativa de conciliar o tempo de aprendizagem da criança/jovem e o do professor com o tempo da instituição (organização escolar). Marcado pelo relógio, em sua dimensão cronológica, bem como afirma Thiesen (2011), alia-se o tempo natural ao tempo racionalizado, ou seja, relaciona-se o "tempo e espaço da escola com o tempo e espaço da fábrica, que vinculou a formação escolar com qualificação para o trabalho" (THIESEN, 2011, p. 249).

No contexto brasileiro, a escola primária de tempo integral foi mencionada por Anísio Teixeira em 1956, então diretor do Instituto Nacional de Estudos e Pesquisas Educacionais (Inep), como parte de uma pauta socioeducativa comprometida com investimentos e esforços para forjar uma escola pública democrática na qual as diferenças de classe social e de privilégios não encontrariam ressonância, tendo em vista a dimensão igualitária e unificadora (lócus de integração social - escola-parque) que nortearia tal proposta: 
As democracias, porém, sendo regimes de igualdade social e povos unificados, isto é, com igualdade de direitos individuais e sistema de governo de sufrágio universal, não podem prescindir de uma sólida educação comum, a ser dada na escola primária, de currículo completo e dia letivo integral, destinada a preparar o cidadáo nacional e o trabalhador ainda não qualificado e, além disto, estabelecer a base igualitária de oportunidades, de onde irão partir todos, sem limitações hereditárias ou quaisquer outras, para os múltiplos e diversos tipos de educaçáo semi-especializada e especializada, ulteriores à educação primária. [...] A escola primária, visando, acima de tudo, a formaçáo de hábitos de trabalho, de convivência social, de reflexão intelectual, de gôsto e de consciência não pode limitar as suas atividades a menos que o dia completo. Devem e precisam ser de tempo integral para os alunos e servidas por professôres de tempo integral (TEIXEIRA, 1956, p. 25-26).

A vivência democrática ratificada pela Constituição Federal impulsionou outras formas de se pensar a escola (BRASIL, 1988). Desse movimento, nasceu uma experiência que norteou a concepção de educação integral no Brasil: a criação do Centro Integrado de Educação Pública (CIEP — Brizolão — , em 1985), idealizado por Darcy Ribeiro, implantado no estado do Rio Janeiro nas décadas de 1980 e 90, sob gestão administrativa de Leonel Brizola. Os CIEPs, projetados pelo arquiteto Oscar Niemeyer, localizados em regióes de alta vulnerabilidade social, tinham um projeto pedagógico que incluía o trabalho articulado entre a experiência cultural, o estudo dirigido e a recreação, atendendo às crianças com tempo ampliado de 10 horas diárias.

No contexto atual brasileiro, a questão da educação de tempo integral vem sendo especialmente retomada em decorrência de a temática integrar a meta 6 do Plano Nacional de Educação em vigência (20142024) (BRASIL, 2014). Além de configurar-se como uma plataforma política daqueles que anseiam uma cidade educadora, trata-se de promover um direito social e dignidade (vivências socioculturais ampliadas) 
a crianças e jovens num cenário árido como a selva de pedras urbana industrial em expansão (ROVERONI, 2017).

A Lei de Diretrizes e Bases da Educação Brasileira (LDB), $\mathrm{n}^{\circ}$ 9.394/96, em alguns de seus artigos, aponta de forma implícita e explícita a questáo do tempo integral:

Art. 34. A jornada escolar no ensino fundamental incluirá pelo menos quatro horas de trabalho efetivo em sala de aula, sendo progressivamente ampliado o periodo de permanência na escola.

$\$ 1^{\circ}$ São ressalvados os casos do ensino noturno e das formas alternativas de organização autorizadas nesta Lei.

$\$ 2^{\circ} O$ ensino fundamental será ministrado progressivamente em tempo integral, a critério dos sistemas de ensino. [...]

Artigo 52 - sobre as instituiçôes de Ensino Superior [...] inciso III - um terço do corpo docente em regime de tempo integral. [...]

Artigo $87[\ldots]-\$ 5^{\circ}$ Serão conjugados todos os esforços objetivando a progressão das redes escolares públicas urbanas de ensino fundamental para o regime de escolas de tempo integral (BRASIL, 1996, grifos nossos).

Quanto à questão da educação integral, a LDB (artigo 29 e artigo $35, \$ 7^{\circ}$ ) faz indicação sobre a finalidade da educação infantil e o currículo do ensino fundamental voltados ao desenvolvimento/formação integral.

Considerando o tempo kairós - aquele do momento oportuno - , surge a problemática deste ensaio: a extensão do tempo na jornada escolar dos educandos, característica dos modelos de educação integral nas escolas públicas do Brasil, pode ser compreendida como tempo oportuno para a transformação, para o processo de humanização e para a transcendência da visão fragmentada do conhecimento, das coisas da vida, dos processos sócio-históricos? 
O que é esse tempo oportuno num momento em que as correlaçóes entre o tempo se redimensionam tendo em vista a produção da energia artificial, com possibilidade de ampliação das horas de vigília; os meios de comunicação; a conectividade também estabelecida pela via de equipamentos de tecnologia avançada que hiperlinkam/interconectam pessoas de diferentes locais, em tempo real, mas artificiais, em que não se discerne verdade (fato/acontecimento) de mentiras forjadas? Como se apropriar de uma quantidade imensa e intensa de informaçóes que metafisicamente criam espaços e possibilidades de construções permeadas por signos de distintas aldeias? Acrescidos em tal aspecto, entre vários outros condicionantes, temos os retrocessos no campo político com a retomada de governos que politicamente se autodenominam de democráticos, mas que são socialmente fascistas, como diria Boaventura de Sousa Santos (2011). Nessa conjuntura, o valor econômico coloca-se como supremacia para orientar políticas e políticos em uma governança historicamente patrimonialista que coloca a escola pública obrigatória como lócus dos necessitados (sem querer generalizar), mais que direito de todos os cidadãos brasileiros. Aspecto que altera drasticamente a relação com os tempos da vida e os significados atribuídos a eles/elas, pois tais tempos acabam por configurar-se como marcadores de classe social e de privilégios mais que visar à promoção dos direitos sociais, à cidadania, entre outros.

\section{TEMPOS DA/NA ESCOLA: ALGUNS APORTES SOBRE AS DIMENSÕES QUANTITATIVA E QUALITATIVA}

Uma medida de tempo quantificável da escolarização em tempo integral pode ser encontrada no Decreto no 6.253, de 13 de novembro de 2007, denominado de Fundo de Manutenção e Desenvolvimento da Educação Básica e de Valorização dos Profissionais da Educação (Fundeb), que esboça uma definição de tempo integral como período mínimo de sete horas diárias de escolarização aos educandos (BRASIL, 2007). Embora exista uma discussão importante sobre a forma como a composiçáo dessa jornada aconteça, quantificar o tempo mínimo de permanência dos educandos nas escolas impóe um impera- 
tivo de mais tempo de vida, regulado pela lógica de funcionamento das instituições escolares.

Em concomitância ao postulado pela legislação, que determina o tempo da escola, existe o tempo na escola, que é vivido e experienciado por inúmeras infâncias. Como tais, ora elas se conformam com as medidas disciplinadoras do tempo relógio, ora elas subvertem essa fragmentação com a sua própria existência. Os assuntos das aulas, os encontros, as brincadeiras, os acontecimentos, os afetos, as brigas - que até podem acontecer em momentos determinados — tendem a extrapolar a hora/aula, o momento definido pelo adulto. Exemplo disso é a fala corrente nas escolas sobre o comportamento dos educandos que "brincam fora de hora!".

É o tempo da escola que se confronta com o tempo na escola. É o que foge à escolarização, mas só acontece por intermédio dela! Perguntamos assim: que tempo é esse que percorre as sensibilidades, as experiências e as vivências de inúmeras crianças que convivem por mais tempo na escola?

Elias (1998) apresenta uma concepção de tempo com base em uma perspectiva humana, histórica e social atrelada ao processo civilizatório das sociedades. A urbanização, as trocas de mercadorias e, depois, o livre comércio e a agricultura apresentaram demandas ao homem de padronização e regularização de suas atividades. Um saber que foi construído e compartilhado por um coletivo até tornar-se universal ou aceito por uma maioria em determinado contexto. As regularidades marcadas pelo instrumento do relógio passam, com o avanço das sociedades, a autodisciplinar os indivíduos diante das exigências das sociedades contemporâneas. O que esse autor enfatiza com relação ao tempo é o fato de ele não constituir-se como um elemento natural da vida dos indivíduos, mas como um saber aprendido, ensinado e aprimorado pelos homens. Assim sendo, as suas problematizaçóes podem considerar as complexidades envolvidas no desenvolvimento da humanidade. Essa perspectiva de tempo auxilia-nos na reflexão sobre os tempos da escola - produto humano - e acerca das formas disciplinadoras a que sujeitamos os educandos quando impomos unicamente um funcionamento baseado no tempo/aula ou no tempo conteúdo/disciplina. 
Coelho (2012) explica-nos que a ideia de educação integral já está posta de modo inerente à ampliação da jornada, isso porque, para consolidar-se e articular o conhecimento, a cultura e o lazer, é preciso mais tempo, contudo essa perspectiva traz, entre vários aspectos, o desafio de refletir sobre o como. Como as políticas públicas de educação integral são implementadas? Como esses tempos são vividos e experienciados pelas crianças/pelos adolescentes? Que projeto de comunidade e educação tais tempos explicitam? Uma educação integral para uma aprendizagem voltada aos valores e princípios humanos essenciais? Uma escola pública voltada a controlar crianças/jovens pobres no contraturno escolar, que poderiam ficar ociosos nas ruas? Uma escola que amplia sua jornada e se volta à transformaçáo ou conservação das contradiçôes socioeconômicas?

Para a promoção de tempos estésicos (sensíveis), como diria João Francisco Duarte Júnior (2001), ou como apontaria Jorge Larossa Bondía (2002), que a escola seja muito mais um lugar que nos toca, que nos marca, que nos faz sentir, mais do que nos indique coisas para fazer e desconecte o trabalho da vida humana. Uma escola em que há desenvolvimento real (VYGOTSKY, 1991), mas para uma utopia de uma comunidade solidária e justa (CHAUÍ, 2008, p. 57).

Freire (2000) defende que toda e qualquer reflexão sobre a ação, principalmente a educativa, deveria se dar de forma crítica, não passiva. Isso significa considerar que as açóes que visam à educação têm como premissa a atividade do ser humano. O sujeito está no mundo ativamente, sendo impactado e influenciado por ele, mas ao mesmo tempo atua e influencia o mundo. $\mathrm{O}$ mundo real, das práticas sociais, é o campo da construção significativa do conhecimento. Enxergar-se como sujeito social, de historicidade, de rememoração, como subjetividade que na inter-relação com outrem se constitui único, singular e, portanto, especial.

O tempo para transformação perpassa pelo questionamento sobre práticas escolares. Freire (2000) questionava as formas de educação por meio da simples memorização e da mecanização dos métodos e das práticas socioeducativos. Sua reflexão residia no campo do apagamento da historicidade do ser humano, que, humano, constrói conhecimento antes de enquadrar-se nos moldes da educação escolarizada. 
Ademais, memorizar de maneira automática não transforma o objeto do conhecimento em si, pois a transformaçáo demanda atividade e reflexão do sujeito sobre o objeto cognoscente. Daí que, para ler o mundo, é preciso antes transformá-lo por meio da nossa ação. O tempo de transformação é aqui, o próprio tempo da vida, o presente. Estando nela de forma mais consciente possível, apreende-se - porque necessário que o conhecimento está na sua transformação e não se constitui de modo inato:

Não se apreende o objeto se não se apreende sua razão de ser. Não é por outra razão que a pura memorizaçáo mecânica do perfil do objeto náo constitui conhecimento cabal do objeto. Daí que, na experiência cognitiva verdadeira, a memorizaçáo do conhecimento se constitua no ato mesmo de sua produção (FREIRE, 2000, p. 41).

$\mathrm{Na}$ educação integral, essa concepção é primordial para balizar a construção do currículo e do tempo escolar. Se não se apreende o objeto somente porque ele existe no mundo da realidade, torna-se responsabilidade da escola significar esse objeto, para que daí decorra um conjunto de situações (atividades mediadas) necessárias para o aprender. O dilema aumenta quando pensamos nas atividades que preenchem o tempo a mais nas escolas de educação integral. Temos mais tempo para emancipação/ transformação ou mais tempo para memorização mecânica do rol de conteúdos eleitos pela escola? Essa forma de ler o mundo e estar nele, na qual o conhecimento náo é algo dado que se deposita na cabeça dos educandos, tampouco algo que acontece por repetição em si, modifica e ressignifica o trabalho na escola (ROVERONI, 2017; GUIMARÃES, 2017). Não precisamos de mais tempo para memorizar conteúdo; precisamos de mais tempo para propor e participar das transformaçóes. Retomamos aqui uma das assertivas desse ensaio: como se apropriar do tempo — qual(is) significado(s) atribuir a ele? — , aquele do momento oportuno, para apreender quais são as razóes de ser dos sujeitos e objetos, além de como foram concebidos pela humanidade e como se empregam nas relações sociais? 
A relação que marca a vida de quem ensina e de quem aprende é por Freire (2000) concebida como não linear. Ela não se inicia no professor nem acaba na criança/no adolescente. Esse caminho, que é inseparável — não existe aprender sem ensinar — , é cíclico, vivo, envolve apropriação e criação de cultura - criação cultural que da escola de tempo integral pode emergir.

Qual é o mundo de possibilidade que uma educação integral viabiliza? A sua própria concretude, na qual está presente de forma majoritária a classe popular, pode servir para a retomada de um pensamento mais crítico? A escola de tempo integral pode ser um mundo no qual o educando atua não por meio de simulacros, mas de forma concreta e real, e, atuando, elabora outra consciência de si e do mundo?

\section{CONSIDERAÇÕES}

Com essa reflexão, buscou-se evidenciar algumas características do elemento tempo na discussão da educação integral e da escola de tempo integral, estabelecendo um paralelo entre o tempo da escola e o tempo na escola, o que nos permitiu também atividade reflexiva sobre o próprio tempo. Longe de esgotar as possibilidades analíticas em torno de um tema tão instigante, findamos tendo em mente novos começos, para outros tempos vindouros.

O que consideramos ao final desse exercício se situa no campo das possibilidades. Uma delas consiste no fato de a escola de tempo integral e uma educaçáo integral serem passíveis de se consubstanciarem em uma unidade orgânica e transformadora desde que se problematize a instituição escolar socialmente constituída e se assuma um desafio de reinvenção de um contexto socioeducativo, intersetorial e multicultural compromissado com as pessoas, a vida e os direitos humanos, e menos com o capital e as elites detentoras dos poderes.

Outra alternativa é o investimento de tempo na escola e da escola para a construção de um projeto humano sensível às diferenças e aos afetos, que se aproprie de uma concepção de sociedade engajada com o eu, com o outro e com o nós, para além do consumo, do 
hedonismo e da opressão de uns pelos outros, imposta por um lógica de tempo em que náo há tempo a perder. Na perspectiva de construção desse projeto, a escola pode se tornar um espaço com menos fragmentos de coisas para aprender e mais intensa de significados, experiências, experimentaçóes, sabores, saberes e relacionamentos; vinculado a um modo de vida singelo e mais próximo à natureza. Reivindicamos tempo também para uma educação das relações — de respeito - menos agressivas, menos consumistas e menos competitivas/classificatórias, em que as notas possam compor uma melodia, uma canção inspiradora e sensível e menos excludente, sem exposição nem/ou constrangimento.

Nesse projeto de tempo que manifestamos para a educação integral, a educação busca promover os direitos de todos, e não privilégios em nome de direitos corporativos ou minoritários, e tem a liberdade política de engajar-se com a paz e com a fraternidade de pessoas e povos. Queremos o direito ao tempo da escola com a perspectiva humana, para todas as crianças. Que elas tenham assegurados tempo de estar num espaço protegido, uma alimentação gostosa e nutritiva, que possam brincar, estar entre os seus e que tudo isso seja reconhecido como atividade intelectual.

Apresentamos algumas, mas são várias as perspectivas que se apontam quando se trata de dimensionar projetos, planos, programas e ações no campo da política, do trabalho humano. Daí a grandeza humana em sua inventividade, que, por sua vez, não precede ao diálogo nem ao posicionamento de cada um e de todos sobre o projeto de sociedade em sua dimensão (in)finita, material, imaterial e temporal.

\section{REFERÊNCIAS}

BONDÍA, Jorge Larrosa. Notas sobre a experiência e o saber de experiência. Revista Brasileira de Educação, n. 19, p. 20-28, 2002. http://dx.doi.org/10.1590/S1413$\underline{24782002000100003}$

BRASIL. Constituição da República Federativa do Brasil. Brasília: Senado Federal; Centro Gráfico, 1988. 
BRASIL. Decreto $n^{\circ}$ 6.253, de 13 de novembro de 2007. Dispóe sobre o Fundo de Manutenção e Desenvolvimento da Educação Básica e de Valorizaçáo dos Profissionais da Educaçấo - FUNDEB, regulamenta a Lei no 11.494, de 20 de junho de 2007, e dá outras providências. Brasília, 2007.

Plano Nacional de Educação (PNE) 2014-2024: Lei no 13.005, de 25 de junho de 2014, que aprova o Plano Nacional de Educação (PNE) e dá outras providências. Brasília: Câmara dos Deputados, Ediçóes Câmara, 2014. 86 p. (Série Legislação, no 125. )

- Presidência da República. Casa Civil. Subchefia para Assuntos Jurídicos. Lei no 9.394, de 20/12/1996 - Lei de Diretrizes e Bases da Educação Nacional. Brasil, 1996. Disponível em: <http://www.planalto.gov.br/ccivil 03/ leis/L9394.htm>. Acesso em: 11 out. 2017.

CHAUÍ, M. Cultura e democracia. Crítica y Emancipación, Buenos Aires, ano 1, n. 1, 2008.

COELHO, L. M. C. da C. Alunos no Ensino Fundamental, ampliação da jornada escolar e educação integral. Educar em Revista, Curitiba, n. 45, p. 73-89, jul./set. 2012.

DUARTE JÚNIOR, J. F. O sentido dos sentidos: a educação (do) sensível. Curitiba: Criar, 2001. 225 p.

ELIAS, N. Sobre o Tempo. Rio de Janeiro: Jorge Zahar, 1998.

ESCOLANO BENITO, A. Tiempos y espacios para la escuela: ensayos históricos. Madrid: Biblioteca Nueva, 2000.

FREIRE, P. Pedagogia da Indignação: cartas pedagógicas e outros escritos. São Paulo: Editora Unesp, 2000.

GOERGEN,P.L.Espaçoetemponaescola:constataçôeseexpectativas.In:FÓRUM PERMANENTE DE DESAFIOS DO MAGISTÉRIO, 2005., Campinas. Anais [...]. 2005. Disponível em: $\leq$ http://www.scielo.br/scielo.php?script=sci nlinks\&ref $=000126 \& \mathrm{pid}=$ S0102-4698201100010001100011\&lng $=\mathrm{pt}>$. Acesso em: ago. 2019.

GUIMARÁES, B. C. Tempos e espaços de construção coletiva do Projeto Político Pedagógico de uma instituição de educação infantil universitária: um estudo de caso. Trabalho de conclusão de curso (Pedagogia) - Faculdade de Educação, Universidade Estadual de Campinas, Campinas, 2017. 
ROVERONI, M. Escola de Educação Integral de Campinas. Qualificação (Doutorado) - Programa de Pós-graduação em Educação, Faculdade de Educação, Universidade Estadual de Campinas, Campinas, 2017.

SANTOS, B. S. Epistemologías del Sur. Utopia y Praxis Latinoamericana, ano 16, n. 54, p. 17-39, jul.-set. 2011.

TEIXEIRA, A. A escola pública universal e gratuita. Revista Brasileira de Estudos Pedagógicos, Rio de Janeiro, v. 26, n. 64, p. 3-27, out./dez. 1956.

THIESEN, J. da S. Tempos e espaços na organização curricular: uma reflexão sobre a dinâmica dos processos escolares. Educação em Revista, Belo Horizonte, v. 27, n. 1, p. 241-260, abr. 2011. Disponível em: $\leq$ http://www. scielo.br/scielo.php?script=sci arttext\&pid=S0102-46982011000100011\&ln $\mathrm{g}=\mathrm{pt} \& \mathrm{nrm}=$ iso $>$. Acesso em: 10 abr. 2017. http://dx.doi.org/10.1590/S010246982011000100011

VYGOTSKY, L. S. A formação social da mente. 4. ed. São Paulo: Martins Fontes, 1991.

Recebido em 20 de março de 2019.

Aprovado em $1^{\circ}$ de julho de 2019. 